\title{
A vida escorrendo pelo ralo: as alternativas de existência dos meninos de rua
}

\author{
Maria Dilma Siqueira \\ Universidade Federal do Rio Grande do Norte
}

\begin{abstract}
Para explicar o comportamento infrator de adolescentes foram estudadas as condições de socialização e ressocialização de 116 meninos institucionalizados em Natal. Foram analisados os discursos de 17 sujeitos. As condições de socialização foram marcadas pela pobreza e abandono. $\mathrm{O}$ comportamento delinqüente foi adotado como estratégia de sobrevivência. O discurso dos sujeitos reproduziu a ideologia dominante quando se referiam a si mesmos negativamente e atribuíam seu comportamento delinqüente a características pessoais. A trajetória de vida dos sujeitos, dez anos após o internamento, confirma a ineficácia dos programas de ressocialização. A análise do contexto social mais amplo esclarece que as raízes do comportamento delinqüente encontram-se na exploração das classes trabalhadoras pelo modelo de acumulação capitalista adotado no Brasil.

Palavras-chave: Delinqüência juvenil, Socialização, Meninos de rua.
\end{abstract}

$\mathrm{N}$ os anos 50/60 proliferaram explicações para a criminalidade juvenil, notadamente nos EUA, onde gangs de adolescentes organizavam-se na periferia das grandes cidades. De acordo com essas explicações, o delinqüiente-padrão vinha de um lar desorganizado, não havia interiorizado satisfatoriamente as regras morais, tinha péssi- 
mo desempenho escolar, auto-estima baixa, andava em companhia de meninos desajustados e acabava preso por crime contra o patrimônio... Via de regra, passava a associar-se a alguma gang que lhe dava suporte afetivo e um modelo machista de identificação. Para explicar por que os meninos afetados pelas mesmas circunstâncias não optavam todos pela via do delito, os teóricos identificaram alguns fatores que poderiam proteger os sujeitos da delinquiência, tais como: forte ligação afetiva com uma figura parental que tinha expectativas positivas a seu respeito, sucesso escolar, bom nível de auto-estima. Feldmann (1979), apresenta um elenco dessas teorias que, sem maiores problemas, podem ser transplantadas para qualquer contexto social moderno. Porém, sua utilidade limita-se à identificação das mediações do comportamento infrator, não sendo de grande valia para esclarecer as origens da criminalidade juvenil como um problema social, nem as inter-relações entre as socializações mal sucedidas e os determinantes do problema. Para este propósito, as abordagens críticas, com bases no materialismo histórico, proporcionam melhor compreensão da evolução do fenômeno da criminalidade. Nesta perspectiva, as características comportamentais dos indivíduos ganham sentido na dinâmica do processo de socialização levando em conta as determinações decorrentes do modo de produção das sociedades proprietárias. Traumas familiares, falhas educacionais, más companhias, desemprego e pobreza não são considerados fatores determinantes de transgressões, mas mediadores entre o contexto social mais amplo e o comportamento delinqüente.

Este é o relato, muito sucinto, de um conjunto de observações da trajetória de vida de meninos institucionalizados no Centro de Ressocialização de Menores (CRM) de Natal (RN), no período de 1971 a 1981 . As observações foram sistematizadas em quatro estudos, tendo sido os três primeiros relatados numa dissertação de mestrado apresentada ao Departamento de Educação da UFRN em 1982 (Siqueira, 1982). O quarto e último estudo, feito dez anos após a conclusão dos três primeiros, foi relatado no XXV Congresso Internacional de Psicologia, realizado na Bélgica, em 1992 (Siqueira, 1992). 
Os estudos foram realizados da perspectiva das teorias críticas da criminalidade, especialmente dos trabalhos de Taylor, Wlaton e Young (1980). O referencial teórico proposto por Berger e Luckmann (1978) facilitou a análise do processo de socialização dos sujeitos. O conjunto das observações realizadas possibilitaram a construção de um esboço de modelo de socialização das crianças economicamente desfavorecidas e a comprovação das alternativas trágicas reservadas a sua existência.

Estudo 1. Caracterização dos meninos institucionalizados como infratores em Natal (RN)

Foram sujeitos deste estudo, 116 adolescentes do sexo masculino, institucionalizados no CRM, nos anos de 1971 a 1981. A caracterização dos meninos foi feita através da sistematização de todas as informações existentes na instituição, contidas nos prontuários: idade, situação familiar, escolarização e motivo da prisão.

Os resultados mostraram que o perfil dos meninos institucionalizados em Natal confere com os relatos de outras cidades brasileiras já por demais divulgados pela imprensa. A característica mais marcante é a precariedade das condições de subsistência e a acentuada desagregação de suas famílias. Cerca de $61 \%$ dos pais moravam em Natal e sobreviviam às custas de emprego modesto ou subemprego. Apenas 27,6\% eram provenientes da zona rural e somente $2,6 \%$ dos pais viviam juntos. Por ocasião da apreensão pela polícia, aproximadamente $40 \%$ dos meninos estavam completamente abandonados.

Observou-se que $12 \%$ dos meninos eram analfabetos e $48,4 \%$ passaram menos de quatro anos na escola. Haviam sido expulsos por indisciplina ou evadiram-se por conta própria.

A maior parte dos meninos estudados foi institucionalizada na faixa etária de 14 a 16 anos (52,8\%). A maioria dos delitos que motivou a institucionalização é categorizada pela polícia como "crime contra o patrimônio" (53\%), seguido de homicídio $(11,4 \%)$, lesões corporais $(6,9 \%)$, uso de tóxicos e entorpecentes $(5,2 \%)$, perambulações $(4,4 \%)$ e ocorrências não especificadas $(6,1 \%)$. 
A caracterização da clientela do CRM comprovou a precariedade das condições de vida dos jovens institucionalizados como infratores em Natal (RN), assim como a relação entre a miséria econômica e o estado de abandono em que se encontravam ao serem apreendidos. O tipo de comportamento que motivou os internamentos (na maioria, "crimes contra a propriedade") apontou o caráter instrumental das infrações cometidas.

Por ocasião desse levantamento a instituição não mantinha controle do destino dos meninos institucionalizados.

\section{Estudo 2. A vida dos meninos de rua - Natal (RN)}

Nesta etapa do trabalho foram feitos estudos de caso de 17 meninos conduzidos ao CRM nos anos de 79 a 81. Após constatar que os sujeitos eram "típicos" em relação à caracterização do Estudo 1, realizaram-se entrevistas com os meninos, familiares, professores e companheiros de rua. Fez-se, também, uma avaliação das práticas de ressocialização da instituição e seu impacto na vida dos sujeitos.

As entrevistas e observações mostraram que os pais, sem condições para manter suas crianças, estimulavam suas tentativas de buscar sobrevivência na rua. A partir dos 5 anos, as crianças começavam a pedir esmolas ou a acompanhar os meninos maiores nas suas andanças e demonstraram muita criatividade no desenvolvimento de estratégias de sobrevivência. Basta lembrar que, nos anos 70, os meninos se organizaram no espaço das principais ruas das cidades brasileiras e "forçaram" a criação de um mercado de trabalho absolutamente desnecessário. Pastorar carros tornou-se a principal fonte de renda dos meninos da rua e, com o aumento do desemprego, acabou sendo uma das atividades mais disputadas por adultos desempregados. Outras atividades desenvolvidas pelos meninos de Natal foram: lavar carros, vender frutas, doces e picolé, especialmente nas proximidades de semáforos onde os automóveis eram forçados a parar.

Inicialmente, os meninos conseguiram sustentar-se sem a ajuda dos pais, depois passaram a ajudar aos próprios familiares. Essa inversão de modelo de vida acabou por subverter 
os valores tradicionais, especialmente as representações sociais da criança. Estudos paralelos realizados no início dos anos 80 pelos alunos de psicologia da UFRN, como exercício acadêmico, mostraram que, dependendo da sua origem social, a criança poderia ser percebida como um ser inocente, dependente, carente, etc., ou alguém esperto, perigoso e ameaçador. Através de entrevistas com pessoas que transitavam nos pontos de permanência dos meninos chegou-se a constatar que a mesma criança despertava pena, medo, repulsa e vontade de ajudar.

$\mathrm{Na}$ rua, os meninos tiveram oportunidade de aprender a cometer furtos, roubos e assaltos. Alguns deles começaram a se envolver com drogas e traficantes adultos. Foram presos muitas vezes e relataram espancamento e ameaças sofridas nas delegacias.

A idade dos 17 sujeitos na época da institucionalização variava de 12 a 17 anos e $71,3 \%$ dos seus delitos foram registrados como crimes contra a propriedade: furtos, assaltos, assaltos com homicídio ou lesões corporais.

A instituição refletiu as mesmas falhas da assistência social em todo o pais. $\mathrm{O}$ confinamento não proporcionou aos meninos oportunidades de aprendizado formal nem consciência social, nenhuma formação profissional nem chances de ocupação. Não houve continuidade nos programas educacionais devido as fugas constantes. Houve muitas oportunidades para experiências traumáticas, inclusive estupros por internos maiores ou agressivos e contatos com grupos delinqüentes e drogas. A institucionalização reforçou a estigmatização social dos sujeitos dificultando sua reintegração. Dessa forma, o internamento afigurou-se como instrumento de controle e manutenção da ordem .

Estudo 3 - Aspectos da subjetividade dos meninos de rua

A partir da análise do conteúdo de entrevistas gravadas, pode-se estudar as percepções que os sujeitos desenvolveram sobre suas condições de existência e seus projetos de vida, conforme o método desenvolvido por Hiernaux (1977) e Remy (1976). 
A análise revelou a internalização das concepções dominantes acerca da condição delinqüente. O infrator é o indivíduo vagabundo que não trabalha, que rouba e faz miséria. A identidade como ser humano também foi afetada, pois o vagabundo não tem consciência nem piedade, é como um animal. Seu interior é negativo e necessita controle externo. $\mathrm{O}$ espaço natural do infrator é a margem da sociedade, na favela (extensão do seu interior descontrolado).

A condição delinqüente foi explicada como opção pessoal, maldade natural, intervenção de maus espíritos, má influência dos companheiros porém, nunca justificada pelo estado de carência ou pela condição social. A opção pessoal foi instigada pela necessidade de prazer decorrente do "vício", logo, por motivação de excesso e não de sobrevivência. Este dado contrasta com a aplicação do dinheiro obtido nos delitos, a maior parte gasta em alimentação.

A ausência de consciência de classe social levou à identificação dos companheiros como oponentes e não a própria estrutura da sociedade. Percebiam porém, as barreiras da estigmatização, assim como o valor do dinheiro e do trabalho como meio de inserção na sociedade.

É possível que o momento em que foram feitas as entrevistas (durante as incursões de um grupo de extermínio - Mão Branca- e explorações jornalísticas), tenha reforçado a tensão frente a perspectiva do final trágico da vida delinqüente a perdição e a orientação positiva para a Vida e a Salvação. Observaram-se, no entanto, diferenças quanto à significação emprestada a Salvação. Os internos mais antigos pareceram mais influenciados pelos padrões morais e demonstraram sentimento de culpa pela sua conduta delinqüente. A identidade projetada parece ter sido modelada nas representações sociais dominantes de homem de bem e individuo que cumpre as regras sociais. Assim, o castigo ou punição é legitimado porque faz parte das "regras" estabelecidas naturalmente (errar é humano, quando por inexperiência, continuar errando é descer a condição infra-humana).

Um interno recém chegado mostrou-se mais voltado para o prazer, condicionando o ajustamento da conduta à posse do 
dinheiro para adquirir drogas. Na sua percepção o viciado com dinheiro, numa cidade grande, não é importunado nem estigmatizado, isso é o que importa. É possível que essas diferenças devam-se às preleções recebidas pelos internos na Delegacia de Menores, no CRM, ou a assistência religiosa recebida durante algumas ocasiões. Todos os entrevistados valorizaram igualmente as dimensões de espaço exterior e tempo futuro e percebiam o espaço interno, o presente e o passado, negativamente.

Estudo 4. Avaliação do destino dos 17 sujeitos até dezembro de 1991 (dez anos após a realização do Estudo 3), através de informações obtidas com seus parentes, companheiros, técnicos da instituição e noticiário policial.

A avaliação da trajetória de vida dos 17 adolescentes dez anos após seu internamento no CRM confirma a ineficiência dos programas de ressocialização, tal como pode serobservado na Figura 1. Em dezembro de 1991, sete sujeitos (41\%), estavam em liberdade. Dois deles foram para a Cidade Grande; dois viviam na zona rural do Rio Grade do Norte e três viviam em Natal. Estes últimos, ocasionalmente praticavam pequenos furtos. Eles não se profissionalizaram e sobreviviam de "biscates";

Quatro sujeitos (24\%) continuaram sua vida delinqüente e estavam presos na Colônia Penal . Um deles assassinou um companheiro de cela, também sujeito desta pesquisa. Sua incorporação "à vida social normal" não foi possibilitada porque significava "produzir e ganhar", ao invés de "não produzir e roubar". E como um indivíduo estigmatizado poderia encontrar trabalho que lhe assegurasse a sobrevivência numa sociedade que dispunha de enormes contigentes de desempregados, com passado conformista, dispostos a aceitar salários ínfimos?

Seis sujeitos $(35 \%)$ tiveram morte violenta: dois assassinados por companheiros, em Natal, dois pela polícia paulista (um deles durante a tentativa de fuga da prisão, em São Paulo; o outro foi pego na ocasião e morreu alguns dias após ter sido torturado); os outros dois sujeitos foram executados pelo Grupo de Extermínio, Mão Branca, em Natal. 
Figura 1 - O destino dos 17 sujeitos

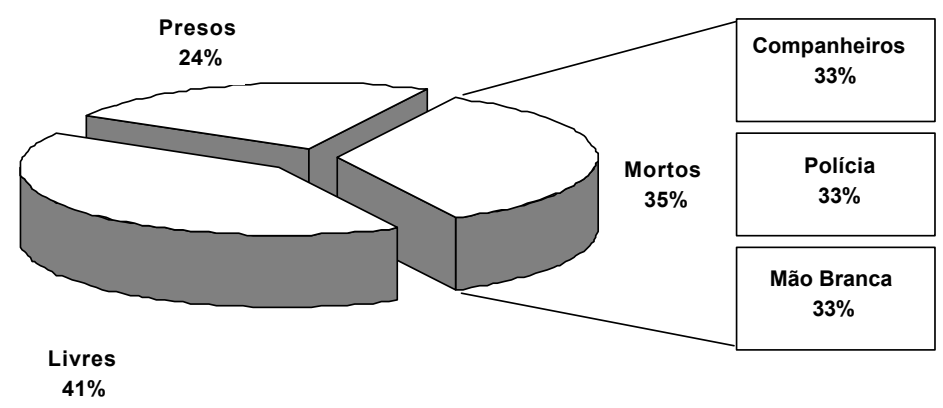

\section{O contexto social de socialização dos sujeitos}

Em Natal, como no resto do País, a delinqüência juvenil é apenas mais um dos inúmeros problemas sociais resultante da miséria e abandono a que foram relegadas as camadas mais pobres da sociedade. Essa miséria e abandono que caracterizavam a condição dos sujeitos não surgiram repentinamente nos anos 60 mas, o crescente agravamento dos problemas sociais verificado naquela década, decorreria, segundo muitas análises, do modelo de acumulação de capital implantado pelo Governo Militar, muito bem respaldado por um aparato político-ideológico e garantido por um aparelho policial sem precedentes na nossa história.

O dinamismo econômico verificado no período de 69 a 73 permitiu ao país ultrapassar a condição de subdesenvolvimento graças à abertura externa da economia, possibilitou grandes investimentos do capital estrangeiro e a ampliação do campo de ação dos intermediários financeiros no mercado. Priorizou-se o desenvolvimento das indústrias de bens duráveis de consumo destinados às classes alta e média, cujo poder aquisitivo foi aumentado significativamente, para garantir o mercado interno (inclusive com a expansão do sistema de crédito ao consumidor) e atender aos interesses dos intermediários financeiros. Essas medidas garantiram o su- 
cesso do chamado "Milagre Brasileiro" de vida curta mas nefastas consequiências para as classes trabalhadoras. Apesar do considerável aumento do produto interno, a economia do País não atingiu autonomia na capacidade de auto transformação e por voltas de 1973 entrou em desaceleração. O milagre apresentou os primeiros sintomas de fracasso: diminuição dos lucros de alguns setores, retração de investimentos e, sobretudo, incontroláveis taxas inflacionárias. Ficou evidente o caráter desastroso da nova política econômica: o agravamento da dívida externa e a superexploração das classes trabalhadoras que tiveram seus salários reais progressivamente reduzidos (Freire, 1979; Furtado, 1981, entre outros).

A concentração de renda, que já se manifestava forte em $1960(54,35 \%$ da renda total retidos por apenas $20 \%$ da população ativa), tornou-se ainda mais aguda em 76 (64\% da renda retidos pelos $20 \%$ mais ricos).

As dificuldades das classes trabalhadoras relacionavamse, ainda, com a situação do meio rural, onde predominavam os grandes latifúndios e as pequenas propriedades familiares. Sem acesso às melhores terras nem às técnicas modernas, restava aos agricultores pobres a possibilidade de incorporação aos latifúndios, empresas agrícolas ou conformarem-se à condição de migrantes.

A mão-de-obra excedente no campo uniu-se aos contingentes de desempregados para compor o chamado exército industrial de reserva. Pela lei de oferta e procura, o exército industrial de reserva cumpriria a função de manter baixos os salários, pois possibilitaria a alta rotatividade nas indústrias diminuindo o poder de barganha dos trabalhadores absorvidos, já tão sufocados pela política de segurança que suportou o modelo econômico brasileiro. Como esclarece Pereira (1978), um sistema capitalista periférico, assim como o brasileiro, diferencia-se do sistema econômico capitalista central, clássico ou contemporâneo, quanto ao fator trabalho, pela debilidade crônica de demanda de força de trabalho. Assim sendo, além do exército de reserva, formar-se-ia uma nova parcela potencialmente ativa, que constituiria o excedente do exército industrial de reserva. Esta população excedente é 
identificada como a população ainda mais instável no sistema econômico capitalista periférico. Todavia, estas parcelas marginais não se diferenciam qualitativamente, pois cumprem junto ao exército industrial de reserva a mesma função de reduzir ou anular seu poder de barganha no mercado de trabalho e tornar instável sua incorporação ao processo produtivo. Conforme Pereira (1978), essa população, cuja existência foi denominada participação-exclusão, tende a ser expelida e extinta "pela fome inclusive", no sistema capitalista periférico, em determinado estágio do seu desenvolvimento (p.154).

Dessa perspectiva, os índices de mortalidade infantil exemplificam os mecanismos de exclusão e extinção da população excedente. Conforme Furtado (1981), de quatro milhões de crianças nascidas nos anos 70, cerca de 360 mil morriam durante o primeiro ano de vida. Isto significava, na época, um índice de mortalidade infantil de duas a três vezes superior ao dos países do mesmo nível de renda.

Os problemas que afetaram as classes trabalhadoras brasileiras nos anos 60-70 intensificaram-se na região Nordeste, onde as desigualdades sociais foram mais acentuadas. $\mathrm{O}$ processo de industrialização, promovido pela SUDENE e liderado pelas grandes empresas do Centro-Sul, seguiu a lógica geral do modelo capitalista brasileiro.

O perfil Estatístico das Crianças e Mães no Brasil, traçado pelo UNICEF e (Brasil, 1982), mostrou que a maioria das famílias nordestinas vivia em precárias condições, dispondo apenas de renda per capita de até meiosalário mínimo. Assim, nos anos de 70-77, estimava-se que $81 \%$ das crianças residiam em domicílios sem canalização interna e $84 \%$ eram sujeitas à contaminação, pela ausência de instalações sanitárias.

No Rio Grande do Norte, local de procedência de quase totalidade dos sujeitos estudados, a capacidade de gerar empregos permaneceu ainda mais baixa que no Nordeste como um todo. Em 1970 estimava-se que 97 mil pessoas eram absorvidas pelo mercado de trabalho, enquanto que 103 mil se encontravam desempregadas e 273 mil, subempregadas.

As dificuldades de trabalho no campo, agravadas por sucessivas estiagens, provavelmente acarretaram migrações e 
reforçaram os contigentes de subempregados nas principais cidades do Estado. Em 1980, a população urbana já superava a rural e o setor agrário demonstrava significativa redução de sua capacidade de absorção de mão de obra ativa. Conforme dados apresentados por Silva (1980), naquele ano, o setor secundário ocupou apenas $20 \%$ da população, verificando-se um grande avanço no setor terciário ou de serviços $(38,1 \%)$.Conforme o Diagnóstico Estrutural do Estado, do Governo do Estado do Rio Grande do Norte (1976), o aumento do terciário costuma decorrer da expansão do subemprego e empreguismo no aparelho burocrático.

Em 1970, 62,55\% das famílias do Rio Grande do Norte viviam em estado de pobreza absoluta, percebendo mensalmente quantia inferior ao salário mínimo regional, ou seja Cr\$125,00 (o salário mínimo da época correspondia a $\mathrm{Cr} \$ 144,00)$. Apenas 2,3\% das famílias retinham mensalmente quantia superior a $\mathrm{Cr} \$ 1.000,00$.

Diante desse quadro, não causa estranheza as constatações da CPI do Menor, realizada pela Câmara dos Deputados, em 1976, de que no nordeste se concentrava o maior percentual de menores abandonados do país $(44,77 \%)$, o maior número de carentes $(37,68 \%)$ e um percentual de delitos cometidos por adolescentes em torno de $37,98 \%$, apenas superado pela região sudeste (na época, $44,17 \%$ ).

Inseridas nesse contexto, as histórias individuais dos sujeitos ganham sentido e ficam evidentes as ligações entre a estrutura social e os condicionantes dos padrões comportamentais particulares. 
Esboço de um modelo de socialização das crianças miseráveis do Brasil

1. Condições estruturais: fortes disparidades sociais

2. Mediação: grupos de socialização

Grupo familiar:

Infância abortada: a família não atende as necessidades básicas.

Escola:

Escolarização inexistente ou incompleta.

Vida na rua:

Perambulações, mendicância ou biscates inicia dos aos 5-8 anos idade para sobrevivência própria e da família.

Aprendizado de pequenos delitos na rua.

Enfraquecimento dos laços familiares.

Freqüentes prisões.

Envolvimento com drogas, grupos delinqüentes

e prostituição.

Instituição:

Contato com meninos mais experientes na vida delinqüiente.

Identidade delinqüiente - estigmatização.

3. Destino:

Resignação à vida miserável.

Prisão.

Morte Violenta.

\title{
4. Reprodução
}

\begin{abstract}
Life going down the drain: street boys' living alternatives

In order to explain how the delinquent behavior of Brazilian juveniles is developed, the conditions of socialization and resocialization of 116 institutionalized boys, in Natal-RN, were investigated. The discourses of 17 subjects were analyzed. The adolescent inmate conditions of socialization
\end{abstract}


have been marked with poverty and dereliction. Delinquent behavior starts as a survival strategy. The discourse of subjects reproduces the dominant ideology when they assess themselves negatively and input their delinquent behavior to their own personal characteristics. Trajectory of life of 17 subjects ten years after their internship, confirms the inefficiency of the programs of socialization. The analysis of the broader social context shows that juvenile delinquency roots are in the over exploitation of the lower classes by the capitalist accumulation model prevalent in Brazil.

Key-words: Juvenile delinquency, Socialization, Street boys.

\section{Referências}

Berger, P. L., \& Luckmann, T. (1978). A construção social da realidade: tratado de sociologia do conhecimento. 4. Ed. Petrópolis: Vozes.

Brasil. Fundação IBGE. UNICEF. (1982). O perfil estatístico das crianças e mães no Brasil: características sócio demográficas: 1970-1977. Rio de Janeiro.

Brasil. Câmara dos Deputados. (1976). A realidade brasileira do menor. Brasília, Coordenação de Publicações.

Feldman, M. P. (1979). Comportamento criminoso: uma análise psicológica. Rio de Janeiro: Zahar.

Freire, P. (1979). Multinacionais e trabalhadores no Brasil. São Paulo: Brasiliense.

Furtado, C. (1981). O Brasil pós-milagre. Rio de Janeiro: Paz e Terra.

Governo do Estado do Rio Grande do Norte. (1976). Diagnóstico Estrutural do Estado.

Hiernaux, J-P. (1973). Quelques elements pour l'observation et l'analyse de performances culturelles. Recherches Sociologiques, 4(1), 172-194.

Hiernaux, J-P. (1977). L'institution culturalle: méthode de description structurale. Louvain: Presses Universitaires de Louvain (U.C.L.).

Pereira, L. (1978). Populações marginais. São Paulo: Duas Cidades.

Remy, J. (1976). Introduction a une methode d'analyse structurale elabore dans une perspective d'interpretation sociologique. Manuscrito não-publicado, Universidade Católica de Louvain, Bélgica.

Silva, C. E. L. (1980). A comunicação populista de Aluízio Alves: Rio Grande do Norte. 1960/1980. Manuscrito não-publicado.

Siqueira, M. D. F. (1982). A condição subumana do infrator menor. Dissertação de Mestrado, não publicada. Universidade Federal do Rio Grande do Norte, Natal. 
Siqueira, M. D. F. (1992, julho) Juvenile delinquency in Brazil socialization conditions of adolescents arrested in Natal-RN. Comunicação apresentada no XXV Congresso Internacional de Psicologia, Bruxelas, Bélgica.

Taylor, I., Wlaton, P., \& Young, J. (1980). Criminologia Crítica. Rio de Janeiro: Graal.

Young, J. (1980). Criminologia da classe trabalhadora. In. I. Taylor, P. Walton \& J. Young (Orgs.) Criminologia crítica. Rio de Janeiro: Graal.

Maria Dilma Ferreira Siqueira é professora (aposentada) do Departamento de Psicologia da Universidade Federal do Rio Grande do Norte. Mestre em Educação pela UFRN. Endereço para correspondência: Rua Carvão de Pedra, 10, Lagoa Nova, 59076-010, Natal, RN. E-mail: dilma@digi.com.br. 